\title{
Upper airway dynamics during negative expiratory pressure in apneic and non-apneic awake snorers
}

\author{
A Ferretti ${ }^{1}$, P Giampiccolo ${ }^{2}$, S Redolfi ${ }^{3}$, S Mondini ${ }^{4}$, F Cirignotta ${ }^{4}$, A Cavalli ${ }^{1}$ \\ and C Tantucci*3
}

\begin{abstract}
Address: ${ }^{1}$ Division of Pneumology, S. Orsola-Malpighi Hospital, Bologna, Italy, ${ }^{2}$ Pneumology Unit, ASL, Imola, Italy, ${ }^{3}$ Respiratory Medicine Unit, Department of Internal Medicine, University of Brescia, Italy and ${ }^{4}$ Neurology Unit, S. Orsola-Malpighi Hospital, University of Bologna, Italy

Email: A Ferretti - aferretti@aosp.bo.it; P Giampiccolo - pietro.giampiccolo@fastwebnet.it; S Redolfi - redstefi@inwind.it;

S Mondini - smondini@aosp.bo.it; F Cirignotta - cirignotta@aosp.bo.it; A Cavalli - acavalli@aosp.bo.it; C Tantucci* - tantucci@med.unibs.it

* Corresponding author
\end{abstract}

Published: 30 March 2006

Respiratory Research 2006, 7:54 doi:10.1 186/1465-992I-7-54

This article is available from: http://respiratory-research.com/content/7/1/54

(c) 2006 Ferretti et al; licensee BioMed Central Ltd.

This is an Open Access article distributed under the terms of the Creative Commons Attribution License (http://creativecommons.org/licenses/by/2.0), which permits unrestricted use, distribution, and reproduction in any medium, provided the original work is properly cited.
Received: 23 December 2005

Accepted: 30 March 2006

\begin{abstract}
Background: The ability of negative expiratory pressure (NEP) technique to differentiate between awake snorers with and without obstructive sleep apnea-hypopnea (OSAH) was investigated.
\end{abstract}

Methods: Forty-eight subjects with sleep disordered breathing (SDB) and 7 healthy subjects, as non-snorer controls, underwent the NEP application of -5 and $-7 \mathrm{cmH}_{2} \mathrm{O}$ in the seated and supine position during wakefulness, after performing a sleep study. The upper airway collapsibility was assessed by computing the volume exhaled during the first $0.5 \mathrm{sec}$. $\left(\mathrm{V}, \mathrm{NEP}_{0.5}\right)$ and I sec. $\left(\mathrm{V}, \mathrm{NEP}_{\mathrm{I}}\right)$ following the NEP start.

Results: Patients with severe $(A H I \geq 30)(n=19)$ and mild-to-moderate $(A H I<30$ and $>5)(n=$ 15) OSAH had lower V,NEP $0.5(340 \pm 88 \mathrm{ml})$ as compared to snorers $(A H I \leq 5)(n=14)(427 \pm$ $\mathrm{IOI} \mathrm{ml;}<<0.0 \mathrm{l})$ and controls $(n=7)(492 \pm 69 \mathrm{ml} ; \mathrm{p}<0.00 \mathrm{I})$ in the supine position with NEP -5 $\mathrm{cmH}_{2} \mathrm{O}$. Less significant differences among the different groups were observed for $\mathrm{V}, \mathrm{NEP}_{0.5}$ in the seated position with NEP $-5 \mathrm{cmH}_{2} \mathrm{O}$ and in both positions with NEP $-7 \mathrm{cmH}_{2} \mathrm{O}$ (only OSAH patients vs controls, $\mathrm{p}<0.00 \mathrm{I}$ ). Similar results were obtained for $\mathrm{V}, \mathrm{NEP}$, in either position by using both NEP $-5 \mathrm{cmH}_{2} \mathrm{O}$ and $-7 \mathrm{cmH}_{2} \mathrm{O}$. In spite of this, a substantial overlapping of $\mathrm{V}, \mathrm{NEP}_{0.5}$ and $\mathrm{V}, \mathrm{NEP}$, between snorers and OSAH patients did not allow to identify a reliable diagnostic cut-off level. An inverse correlation with AHI was found for $\mathrm{V}, \mathrm{NEP}_{0.5}$ in the supine position with NEP -5 $\mathrm{cmH}_{2} \mathrm{O}\left(\mathrm{r}_{\mathrm{s}}=-0.46, \mathrm{p}<0.05\right)$ in severe OSAH patients.

Conclusion: The awake OSAH patients exhibit values of $\mathrm{V}, \mathrm{NEP}_{0.5}$ and $\mathrm{V}, \mathrm{NEP}_{\text {, lesser than those }}$ of awake snorers. The NEP technique, however, appears to have a limited usefulness as clinical tool for routine screening of the OSAH patients during wakefulness.

\section{Introduction}

Among the mechanical factors that are believed to promote obstructive sleep apnea/hypopnea (OSAH), the increase in passive upper airway compliance, as assessed by the pharyngeal volume (area)-pressure relationship in the absence of upper airway dilator muscle activity, has 
been repeatedly emphasized [1-6]. This feature influences for a given transmural pressure the end-expiratory crosssectional area at different levels of the upper airways and may be crucial for the development of upper airway narrowing and/or closure at the onset of inspiration during sleep, when the neural activation of upper airway dilator muscles decreases $[7,8]$. Moreover, the patients suffering from OSAH exhibited less negative (sometimes positive) closing (or critical) pressure of the passive upper airways (i.e. the pressure inside the upper airways when they close), as compared to sex, age and body mass index matched snorers and normal subjects [3,9-11]. The increased critical pressure that is considered to reflect a high extraluminal pressure has been ascribed in apneic patients to structural abnormalities such as para-pharyngeal fat deposits in obesity and/or reduced cross-section of bony structures of the lower face in cranio-facial anomalies $[12,13]$. In fact, several observations suggest that either obesity or cranio-facial anomalies would act to increase the tissue pressure surrounding the pharyngeal airway, thus favoring OSAH by reducing the transmural pharyngeal pressure and making the upper airways easier to narrow for a given compliance. In addition, there is compelling evidence that the upper airways have a smaller lumen during wakefulness $[8,13,14]$ and sleep [3] in OSAH patients, who show an increase in the upper airway resistance [15-18], often assuming an anterior-posterior configuration of their major axis with a prevalent lateral narrowing $[8,19]$. These factors tend to increase both the pharyngeal compliance, which is volume and shape dependent, and the closing pressure. Recently, pharyngeal airway length has been found to be greater in OSAH patients, possibly influencing its collapsibility $[20,21]$.

Hence, several, concurrent, inter-related mechanisms (increased compliance, decreased transmural pressure, smaller size and greater length of the upper airways) might enhance the pharyngeal collapsibility in patients with OSAH.

Therefore, simple assessment of upper airway mechanics during wakefulness could identify OSAH subjects and select them for standard polysomnography. In normal awake subjects the application of small negative expiratory pressure (NEP) transients at the onset of resting expiration does not elicit reflex activity of the genioglossus nor changes in upper airway resistance per se $[22,23]$. Under these conditions, the flow dynamics at the beginning of the expiratory phase during NEP application are expected to reflect the mechanical behavior of the pharyngeal airway in a "quasi-passive" condition even during wakefulness. Accordingly, the aim of our study was i) to investigate if volume exhaled during early application of NEP at the onset of quiet expiration at rest was different in OSAH patients, snorers and normal subjects, suggesting different degrees of pharyngeal collapsibility among these groups and ii) if these differences could be used to distinguish non-apneic from apneic snorers.

\section{Methods \\ Subjects}

In a prospective, randomized study we investigated at the Division of Pneumology of the S. Orsola-Malpighi Hospital of Bologna the early expiratory flow dynamics after the application of a small $\left(-5\right.$ to $\left.-7 \mathrm{cmH}_{2} \mathrm{O}\right)$ negative pressure at the mouth in 48 awake male subjects coming from the Neurology Unit who had performed a polysomnographic study in the Sleep Center because of suspected sleep disordered breathing. We excluded those with obvious anatomical defects such as cranio-facial and/or severe otorino-laryngoiatric (ORL) abnormalities, or with neurological and endocrine diseases known to be causally associated with SDB. Subjects affected by cardiac and respiratory disorders capable of causing intra-thoracic tidal expiratory flow limitation (EFL) were also excluded, as well as obese subjects with tidal intra-thoracic EFL in either position. Subjects were not treated with drugs active on CNS or suffered from chronic alcoholism. Among the enrolled subjects 34 resulted affected by obstructive sleep apnea-hypopnea (OSAH) and 14 were snorers without OSAH (Sn). Seven male subjects, non-apneic, non-snorer, as assessed by nocturnal polysomnography, were recruited from the Hospital staff as controls. The study was approved by the local Ethics Committee and an informed consent was obtained from each subject.

\section{Study design \\ Sleep study}

All subjects were examined at the Sleep Center performing an overnight polysomnographic study by recording the following parameters: nasal pressure (by nasal cannula), oral flow (by thermistor), abdominal and rib cage movements (by piezo-sensors), oxygen saturation and heart rate (by finger oxymeter), snoring (by microphone), body movements and body posture. Respiratory events were defined as obstructive apnea in the presence of nose and mouth airflow cessation for at least $10 \mathrm{sec}$ with concomitant inspiratory efforts and as obstructive hypopnea in the presence of discernable inspiratory airflow reduction with inspiratory efforts accompanied by a decrease of $>3 \%$ in oxygen saturation. The results were expressed as the number of apnea and hypopnea per hour of sleep (apneahypopnea index, AHI) [24]. The subjects were categorized according to AHI as non-apneic snorers $(\mathrm{AHI} \leq 5)$ and snorers with mild-to-moderate (AHI $<30$ and $>5$ ) or severe (AHI $\geq 30)$ OSAH.

\section{NEP testing}

Subsequently, the subjects were sent to the Division of Pneumology to evaluate the upper airway mechanics 
looking at the flow-time relationship in the early tidal expiration during strict wakefulness. Expiratory flow dynamics was assessed during the application of a negative expiratory pressure at the mouth (NEP technique). NEP was applied randomly at two different levels, i.e. -5 $\mathrm{cmH}_{2} \mathrm{O}$ and $-7 \mathrm{cmH}_{2} \mathrm{O}$, initially in the seated position and later, 10 minutes after assuming the supine posture. In both positions and at both levels of negative pressure, at least 5 NEP breath-tests were performed at intervals of 510 respiratory cycles, always when the patient had resumed regular breathing according to the spirogram that was continuously displayed on the computer monitor. In this respect, great care was placed to check the level of the end-expiratory lung volume. The expiratory flow recorded under each NEP application was measured in the first 0.5 and $1 \mathrm{sec}$ from the onset of NEP administration to compute by time integration the volume exhaled in these time intervals, labeled hence fore $\mathrm{V}, \mathrm{NEP}_{0.5}$ and $\mathrm{V}, \mathrm{NEP}_{1}$, respectively (Fig. 1). For all subjects in each experimental condition (different posture and negative pressure levels) the mean value of $\mathrm{V}, \mathrm{NEP}_{0.5}$ and $\mathrm{V}, \mathrm{NEP}_{1}$ was calculated, after discarding the highest and the lowest value, by averaging those obtained during at least 3 acceptable NEP maneuvers. It should be noted that the NEP was applied unknown to the subject by a computer at the very onset of the tidal expiration. We also computed the differences between $\mathrm{V}, \mathrm{NEP}_{0.5}$ and $\mathrm{V}, \mathrm{NEP}_{1}$ and the corresponding volumes exhaled during preceding spontaneous expirations $\left(\Delta \mathrm{V}, \mathrm{NEP}_{0.5}\right.$ and $\left.\Delta \mathrm{V}, \mathrm{NEP}_{1}\right)$ in the different groups of subjects. These measurements were performed in both positions and at the same different levels of NEP applied, aiming to normalize in each subject the $\mathrm{V}, \mathrm{NEP}_{0.5}$ and $\mathrm{V}, \mathrm{NEP}_{1}$ values for the baseline expiratory flows and
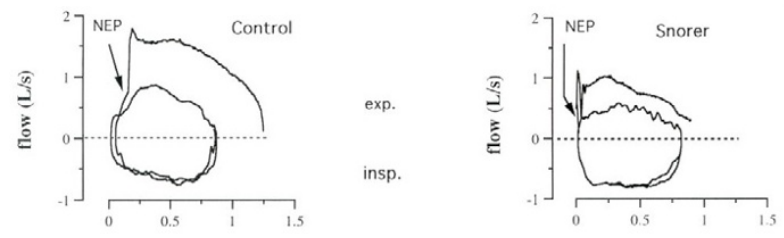

volume (L)
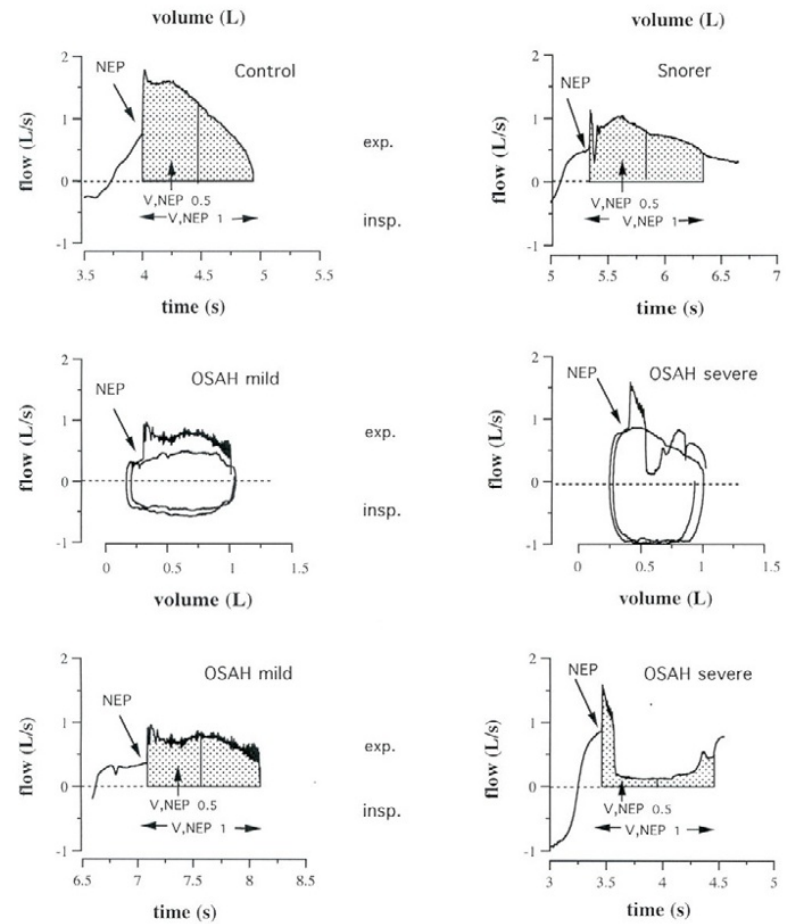

Figure I

Supine tidal flow-volume curves (control and during NEP of $-5 \mathrm{cmH}_{2} \mathrm{O}$ ) and corresponding expiratory flow-time curves (only during NEP) in representative subjects of the different groups. The hatched areas under the flow measure the volume exhaled in the first 0.5 sec. $\left(\mathrm{V}, \mathrm{NEP}_{0.5}\right)$ and I sec. $\left(\mathrm{V}, \mathrm{NEP}_{\mathrm{I}}\right)$ after NEP application. 
volumes. The physician who performed and assessed the NEP tests was blinded to the polysomnographic results.

\section{Pulmonary function testing}

All subjects underwent spirometric measurements using a computerized system (Vmax 22; Sensor Medics, Yorba Linda, CA) in seated position. Slow vital capacity (VC) and three acceptable and reproducible maximal full flow/ volume curves were obtained. Subjects inspired to TLC and then expired forcefully without an end-inspiratory pause to obtain forced vital capacity. The predicted values for volumes and flows were those proposed by the European Community for Coal and Steel [25].

\section{Experimental NEP set-up}

In both seated and supine position, all subjects wearing nose-clips breathed spontaneously room air through a flanged mouthpiece and a heated pneumotachograph (3700 series; Hans Rudolph, Kansas City, MO) connected to a differential pressure transducer (Raytech DP55 \pm 3 $\mathrm{cmH}_{2} \mathrm{O}$; Raytech Instruments, Vancouver, $\mathrm{BC}$, Canada) to measure the flow. The pneumotachograph was linear over the experimental flow range. Volume (V) was obtained by electrical time integration of the flow signal. Pressure was recorded at the mouth (Pm) via a rigid polyethylene catheter (internal diameter $=1.7 \mathrm{~mm}$ ) connected to a differential pressure transducer (Raytech DP55 $\pm 100 \mathrm{cmH}_{2} \mathrm{O}$; Raytech Instruments). The pneumotachograph was assembled in series to a Venturi device that created a negative pressure in the circuit, whose magnitude could be precisely fixed. The application of the negative pressure did not affect the accuracy of the pneumotachograph which measured a flow less than $1 \mathrm{ml} / \mathrm{s}$ when the system was switched on. The Venturi device was connected to a solenoid valve (Asco electrical valve, model 8262G208; Ascoelectric, Ontario, Canada) controlled by a computer and automatically activated when the expiratory flow reached a pre-set threshold value (i.e.: $50 \mathrm{ml} / \mathrm{s}$ ) and after a pre-set time delay (i.e.: $200 \mathrm{~ms}$.) [26]. In all instances the NEP application was timed to last until the lung volume corresponding to the end-expiratory lung volume of the previous control breath was reached or for at least $1.3 \mathrm{sec}$.
The flow and pressure signals were amplified (AC bridge Amplifier-ABC module; Raytech Instruments), filtered through a low-pass filter at $50 \mathrm{~Hz}$, sent to an A/D converter (Direc Physiologic Recording System; Raytech Instruments) connected to an IBM personal computer and sampled at $200 \mathrm{~Hz}$. Both digitized signals were displayed in real time on the computer screen together with the volume signal. The tracings were continuously monitored both with respect to time and as flow/volume curves. All signals were calibrated independently and simultaneously recorded on the hard disk of the computer and were used for subsequent analysis. Data analysis was performed using data analysis software (Direc NEP, version 3.1; Raytech Instruments or Anadat, version 5.2; RHT-InfoDat; Montreal, Quebec, Canada).

\section{Statistical analysis}

Data are presented as mean \pm standard deviation (SD). To assess and verify the normal distribution of the data in each group the Kolmogorov-Smirnov test was performed. Then, one-way ANOVA was used to compare data among groups both in seated and supine position and at different negative pressure and finally multiple comparisons, corrected by the Bonferroni method, were performed between groups, if allowed by the F-value. To assess differences in $\mathrm{V}, \mathrm{NEP}_{0.5}$ and $\mathrm{V}, \mathrm{NEP}_{1}$ within groups between seated and supine posture and different levels of negative pressure a paired Student's test was applied. Correlations between quantitative variables were performed using the Spearman's rank-order test. A p value less than 0.05 was considered statistically significant. The receiver-operating characteristic curves (ROC) were performed to assess sensitivity and specificity of $\mathrm{V}, \mathrm{NEP}_{0.5}$ and $\mathrm{V}, \mathrm{NEP}_{1}$ obtained with different levels of NEP in both positions to get optimal cut-offs.

\section{Results}

The anthropometric and functional characteristics of the subjects are shown in Table 1 . Snorers and OSAH patients were well matched, but patients with severe OSAH were older and had greater BMI than controls $(\mathrm{p}<0.01)$. No correlation, however, was present between $\mathrm{V}, \mathrm{NEP}_{0.5}$ and

Table I: Anthropometric and functional characteristics of subjects.

\begin{tabular}{lcccc}
\hline & Controls & Snorers & OSAH, mild & OSAH, severe \\
\hline Subjects $(\mathrm{n})$ & 7 & 14 & 15 & 19 \\
Age (yrs) & $40 \pm 8$ & $49 \pm 13$ & $49 \pm 10$ & $53 \pm 8 *$ \\
BMI (kg/m $)$ & $24 \pm 3$ & $27 \pm 4$ & $26 \pm 3$ & $29 \pm 3 *$ \\
FEVI (\% pred) & $98 \pm 10$ & $96 \pm 31$ & $103 \pm 25$ & $95 \pm 26$ \\
FVC (\% pred) & $97 \pm 15$ & $96 \pm 24$ & $100 \pm 24$ & $93 \pm 20$ \\
FEVI/FVC (\%) & $88 \pm 12$ & $79 \pm 11$ & $81 \pm 11$ & $86 \pm 1$ \\
AHI & $2 \pm 0.4$ & $4 \pm 2$ & $18 \pm 10$ & $59 \pm 16$
\end{tabular}

$\mathrm{BMI}=$ body mass index; $\mathrm{FEVI}=$ forced expired volume in the first second; FVC = forced vital capacity; OSAH = obstructive sleep apnea-hypopnea; $\mathrm{AHI}=$ apnea-hypopnea index; data are mean $\pm \mathrm{SD} ;{ }^{*} \mathrm{p}<0.01$ vs Controls. 
$\mathrm{V}, \mathrm{NEP}_{1}$ and $\mathrm{BMI}$ in snorers and OSAH patients. None of the subjects had significant restrictive or obstructive ventilatory defect and exhibited tidal intrathoracic EFL in either position during NEP application.

The values (mean $\pm \mathrm{SD}$ ) of $\mathrm{V}, \mathrm{NEP}_{0.5}$ and $\mathrm{V}, \mathrm{NEP}_{1}$, in both positions and NEP levels, are shown in Table 2. The individual $\mathrm{V}, \mathrm{NEP}_{0.5}$ data in each group are shown in Fig. 2. Similar values of $\mathrm{V}_{1} \mathrm{NEP}_{0.5}$ and $\mathrm{V}, \mathrm{NEP}_{1}$ were obtained in subjects with mild-to-moderate and with severe OSAH in all experimental conditions and were treated as a single group for comparative analysis.

$\triangle \mathrm{V}, \mathrm{NEP}_{0.5}$ and $\triangle \mathrm{V}, \mathrm{NEP}_{1}$ reflected exactly what was shown by $\mathrm{V}, \mathrm{NEP}_{0.5}$ and $\mathrm{V}, \mathrm{NEP}_{1}$ with no additional advantage in order to distinguish the different groups. Therefore, we did not consider these time-consuming indices for subsequent analysis.

Within each group $\mathrm{V}, \mathrm{NEP}_{0.5}$ and $\mathrm{V}, \mathrm{NEP}_{1}$ were significantly higher with NEP - $7 \mathrm{cmH}_{2} \mathrm{O}$ than with NEP $-5 \mathrm{cmH}_{2} \mathrm{O}$ in both positions, and with the same negative pressure higher in the seated position than in the supine one $(\mathrm{p}<$ 0.05 for controls, $\mathrm{p}<0.01$ for snorers and patients with OSAH).

The patients with OSAH consistently exhibited values of $\mathrm{V}, \mathrm{NEP}_{0.5}$ and $\mathrm{V}, \mathrm{NEP}_{1}$ much lower than control subjects ( $\mathrm{p}$ $<0.001$ ), but had values of $\mathrm{V}_{1} \mathrm{NEP}_{0.5}$ significantly reduced as compared to snorers only with NEP $-5 \mathrm{cmH}_{2} \mathrm{O}$ in the supine position $(\mathrm{p}<0.01)$ (Fig. 2).

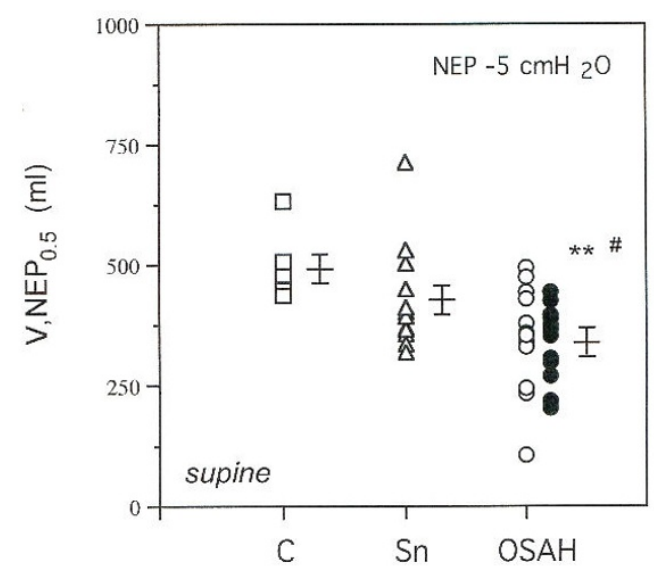

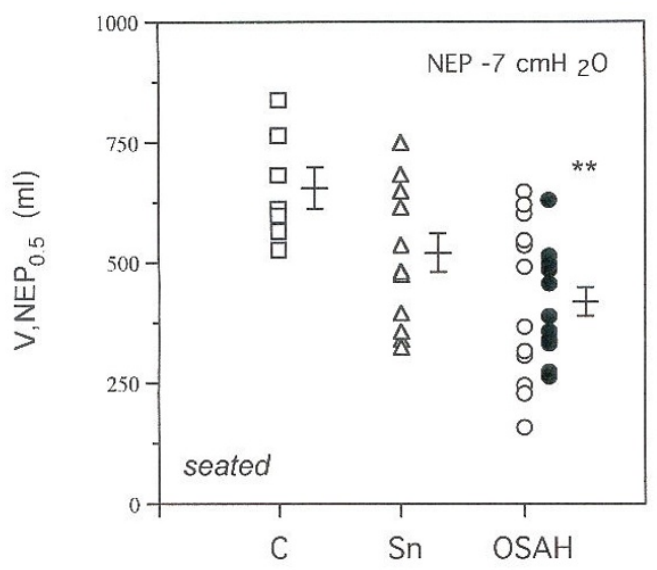
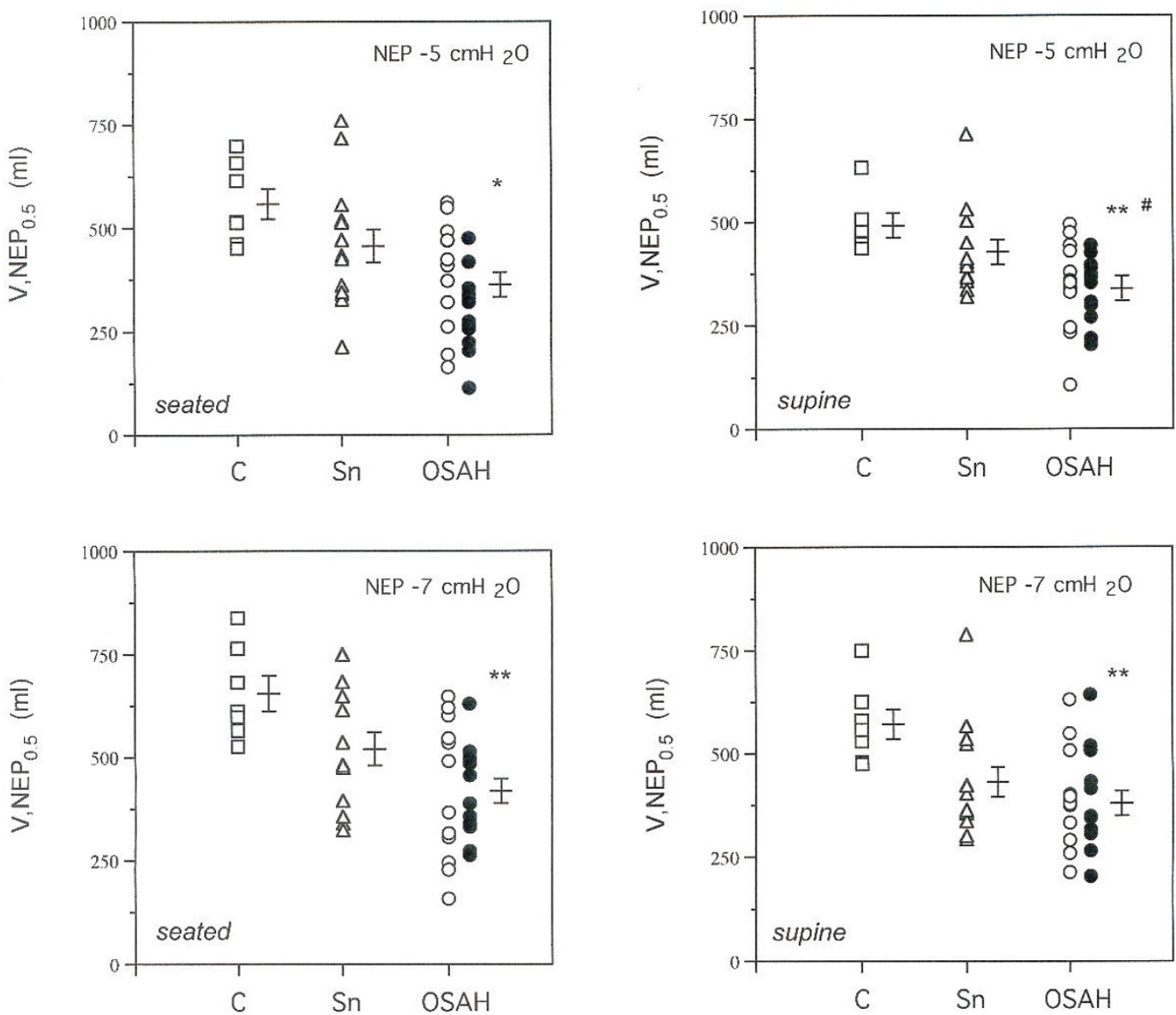

\section{Figure 2}

Individual values of $\mathrm{V}, \mathrm{NEP}_{0.5}$ in seated and supine position at two NEP levels in patients with obstructive sleep apnea-hypopnea (OSAH) (circles, white for mild-to-moderate OSAH and black for severe OSAH), snorers (Sn) (triangles) and controls (C) (squares). ${ }^{*} p<0.0$ I vs $C ; *{ }^{*}<0.001$ vs $C ; \# p<0.05$ vs Sn. 
The receiver operating characteristic (ROC) curves performed for $\mathrm{V}, \mathrm{NEP}_{0.5}$ and $\mathrm{V}, \mathrm{NEP}_{1}$ in both positions at the two different levels of NEP showed similar areas with the highest value for $\mathrm{V}, \mathrm{NEP}_{0.5}$ in the supine position using NEP of $-5 \mathrm{cmH}_{2} \mathrm{O}$ (Fig. 3). Under these conditions, the optimal cut-off $\mathrm{V}, \mathrm{NEP}_{0.5}$ value of $393 \mathrm{ml}$ had a sensitivity of $76 \%$ and a specificity of $74 \%$ to detect the presence of OSAH with a likelihood ratio for positive results of 2.9. Accordingly, its positive and negative predictive value was $84 \%$ and $64 \%$, respectively.

No significant correlation between $\mathrm{V}, \mathrm{NEP}_{0.5}$ (in the supine position with NEP level of $\left.-5 \mathrm{cmH}_{2} \mathrm{O}\right)$ and AHI was observed in patients with OSAH $\left(\mathrm{r}_{\mathrm{s}}=-0.31, \mathrm{r}_{\mathrm{s}}{ }^{2}=0.10\right.$; $95 \% \mathrm{IC}=-0.59-0.04)$. However, taking into account only the patients with severe OSAH (AHI $\geq 30$ ), a significant inverse correlation was found between $\mathrm{V}, \mathrm{NEP}_{0.5}$ and $\mathrm{AHI}$ $\left(\mathrm{p}<0.05 ; \mathrm{r}_{\mathrm{s}}=-0.46, \mathrm{r}_{\mathrm{s}}{ }^{2}=0.21 ; 95 \% \mathrm{IC}=-0.76--0.01\right)$ (Fig. $4)$.

\section{Discussion}

The present study indicates that during wakefulness OSAH patients when compared to snorers and controls have greater collapsibility of the upper airways which can be easily assessed looking at the early expiratory flow dynamics after NEP application during tidal breathing and properly measured as $\mathrm{V}, \mathrm{NEP}_{0.5}$ and $\mathrm{V}, \mathrm{NEP}_{1}$. Such measurements, however, are unable to distinguish on an individual basis apneic from non-apneic snorers because of the overlapping of the $\mathrm{V}, \mathrm{NEP}_{0.5}$ and $\mathrm{V}, \mathrm{NEP}_{1}$ values between these groups of subjects. Nevertheless, our results provide support to the idea that a high degree of the upper airway collapsibility promotes OSAH, even if OSAH may seldom occur in subjects with normal upper airway mechanics during wakefulness, suggesting the involvement of other pathogenetic factors.

Although our snorers had similar age, gender and BMI without obvious cranio-facial and ORL anomalies, lateral cephalometry or MRI studies of the pharynx were not performed, so we cannot exclude minor anatomic abnormalities in bony structure or soft tissue around the pharyngeal airway in OSAH patients. Conversely, careful inspection of the maximal and tidal expiratory flow-volume curves allowed us to rule out the presence of intrathoracic expiratory flow limitation during resting tidal breathing in all subjects. Therefore, we are confident that our subjects had no intrathoracic expiratory flow limitation which might have influenced the upper airway-related expiratory flow dynamics when NEP was applied.

The usefulness of the NEP method to assess the upper airway collapsibility was previously tested in 16 awake subjects known to suffer from sleep-disordered breathing [27]. In contrast to snorers, all patients with OSAH $(n=8)$ showed a substantial portion $(>30 \%)$ of the expiratory tidal volume throughout the NEP application $\left(-5 \mathrm{cmH}_{2} \mathrm{O}\right.$, in the supine position) with lesser expiratory flow than the one recorded during the previous control tidal expiration.

Subsequently, in a group of 19 patients with OSAH when NEP was applied (-5 and $-10 \mathrm{cmH}_{2} \mathrm{O}$, in the supine position) the expiratory flow was reduced, when compared with the corresponding spontaneous expiratory flow, during a relevant part of the tidal expiration $(>20 \%)$ in those $(\mathrm{n}=13)$ with a higher mean apnea-hypopnea index $(\mathrm{AHI})$ [28].

In these studies a significant correlation was found between the percentage of the tidal volume during the NEP application with lower expiratory flow than during the spontaneous breathing and oxygen desaturation index (ODI), in the former, and ODI and AHI, in the latter $[27,28]$. Hence, the NEP method appeared suitable in order to detect an increased pharyngeal collapsibility in patients with OSAH during wakefulness and perhaps able to predict the severity of OSAH.

Recently, using the same criteria, a large cohort of snoring subjects was examined to assess the capacity of the NEP method to screen apneic from non-apneic subjects [29]. In this study a sensitivity of $81.9 \%$ and specificity of $69.1 \%$ in predicting OSAH was found when the expiratory flow during NEP $\left(-5 \mathrm{cmH}_{2} \mathrm{O}\right.$ in supine position) was below that of the previous control expiration for $\geq 27.5 \%$ of the tidal volume. In addition, a significant correlation between NEP induced flow analysis and OSAH severity, as assessed by AHI, was found in the supine position using $5 \mathrm{cmH}_{2} \mathrm{O}$ of NEP with a coefficient value $\left(\mathrm{r}_{\mathrm{s}}=0.51\right)$ similar to the one we obtained in the severe OSAH patients $\left(\mathrm{r}_{\mathrm{s}}\right.$ $=0.46$ ).

All of these studies, however, are based on the assumption that abnormal upper airway collapsibility is present or can be identified only when the expiratory flow during NEP becomes lower than the control one. Moreover, such finding has been erroneously taken as a marker of expiratory flow limitation. In contrast, an increased pharyngeal collapsibility can also be reflected by a smaller increase of expiratory flow during NEP. We believe that this flow has to be measured whether or not it is higher, lower or initially higher and then lower (or vice versa) than the flow of the previous tidal expiration. Indeed, judging as abnormal (or quantifying the severity of) the upper airway collapsibility only by computing the percentage of the tidal volume where the expiratory flow during NEP application becomes lesser than the one exhibited in the previous expiration is a poorly reliable tool. This is because such measure is too dependent from the preceding control tidal 


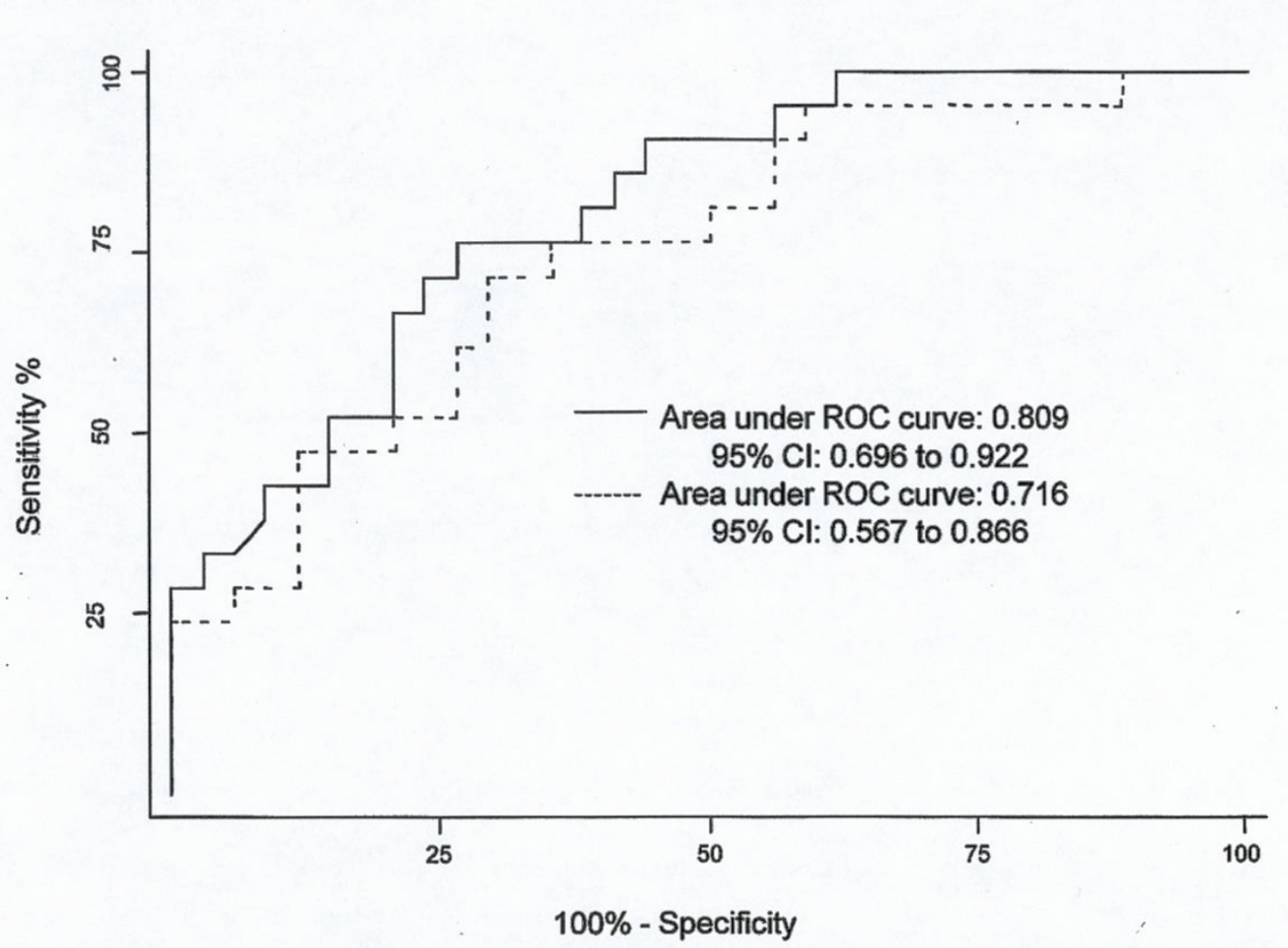

Figure 3

The receiver-operating characteristics (ROC) curves are shown for $\mathrm{V}, \mathrm{NEP}_{0.5}$ values during $\mathrm{NEP}\left(-5 \mathrm{cmH}_{2} \mathrm{O}\right)$ both in supine (continuous line) and seated (dashed line) position in 34 patients with OSAH and 21 subjects without OSAH. The area under the ROC curves reflects the ability of $\mathrm{V}, \mathrm{NEP}_{0.5}$ to distinguish subjects without and with OSAH (AHI>5).

breathing and because the expiratory flow profile is often erratic in the same subject during repeated NEP tests; in addition, several apneic patients do not show such phenomenon constantly [27-29].

Table 2: Values of $\mathrm{V}, \mathrm{NEP}_{0.5}$ and $\mathrm{V}, \mathrm{NEP}$, at two different NEP levels in seated and supine position.

\begin{tabular}{|c|c|c|c|c|}
\hline \multirow[b]{2}{*}{ NEP } & \multicolumn{2}{|c|}{ SEATED } & \multicolumn{2}{|c|}{ SUPINE } \\
\hline & $-5 \mathrm{cmH}_{2} \mathrm{O}$ & $-7 \mathrm{cmH}_{2} \mathrm{O}$ & $-5 \mathrm{cmH}_{2} \mathrm{O}$ & $-7 \mathrm{cmH}_{2} \mathrm{O}$ \\
\hline & \multicolumn{4}{|c|}{$\mathrm{V}, \mathrm{NEP}_{0.5}$} \\
\hline Controls & $559 \pm 98$ & $655 \pm 113$ & $492 \pm 69$ & $571 \pm 96$ \\
\hline Snorers & $457 \pm 150$ & $520 \pm 147$ & $427 \pm 101$ & $430 \pm 134$ \\
\hline OSAH & $363 \pm 123^{*}$ & $419 \pm 132 * *$ & $340 \pm 88^{* *} \#$ & $379 \pm 113^{* *}$ \\
\hline OSAH, m & $402 \pm 129$ & $428 \pm 157$ & $353 \pm 103$ & $387 \pm 108$ \\
\hline \multirow[t]{2}{*}{ OSAH, s } & $332 \pm 112$ & $410 \pm 112$ & $329 \pm 73$ & $372 \pm 119$ \\
\hline & \multicolumn{4}{|c|}{$\mathrm{V}, \mathrm{NEP}_{\mathrm{I}}$} \\
\hline Controls & $1036 \pm 134$ & $1128 \pm 158$ & $832 \pm 95$ & $920 \pm 136$ \\
\hline Snorers & $864 \pm 246$ & $930 \pm 274$ & $737 \pm 194$ & $755 \pm 224$ \\
\hline OSAH & $708 \pm 189 *$ & $781 \pm 210^{*}$ & $628 \pm 136^{*}$ & $669 \pm 177^{*}$ \\
\hline OSAH, m & $732 \pm 202$ & $766 \pm 230$ & $625 \pm 159$ & $666 \pm 178$ \\
\hline OSAH, s & $688 \pm 182$ & $792 \pm 199$ & $629 \pm 120$ & $671 \pm 180$ \\
\hline
\end{tabular}

OSAH = obstructive sleep apnea-hypopnea; $\mathrm{m}=$ mild; $\mathrm{s}=$ severe; data are mean $\pm \mathrm{SD} ;{ }^{*} \mathrm{p}<0.01$ vs Controls; ** $\mathrm{p}<0.00 \mathrm{I}$ vs Controls; \# $\mathrm{p}<0.01$ vs Snorers 


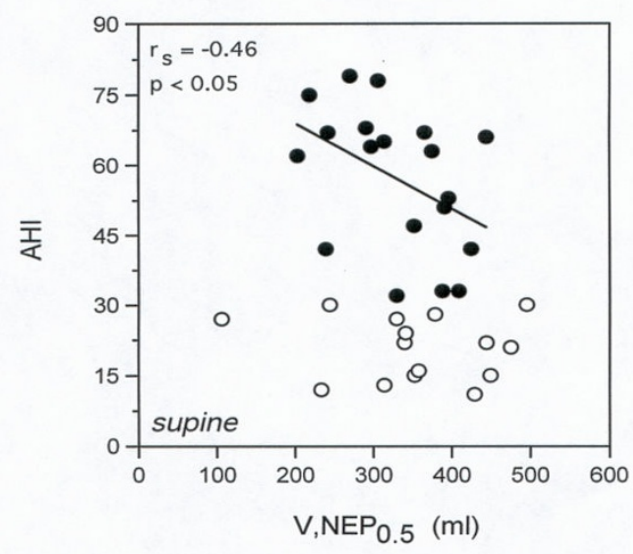

\section{Figure 4}

Relationship between $\mathrm{AHI}$ and $\mathrm{V}, \mathrm{NEP}_{0.5}$ in the supine position during NEP $\left(-5 \mathrm{cmH}_{2} \mathrm{O}\right)$ in OSAH patients (white circles = mild-to-moderate OSAH; black circles = severe OSAH). The regression line refers only to severe OSAH patients.

In order to overcome these problems, recently Tamisier and coll. investigated a quantitative index corresponding to the ratio of the area under the expiratory flow/volume curves between NEP (-5 and $-10 \mathrm{cmH}_{2} \mathrm{O}$ ) and atmospheric pressure for the same tidal volume in awake subjects with sleep disordered breathing (SDB) and control subjects, both in supine and sitting position [30]. They found that this index was significantly different between controls and SDB subjects in all measurements, decreasing with the severity of the SDB. Moreover, in the supine position when $-5 \mathrm{cmH}_{2} \mathrm{O}$ NEP was applied, a given threshold of this index had a positive predictive value of $88.6 \%$ and a negative predictive value of $80 \%$ to screen subjects with SDB. The Authors concluded that the NEPrelated quantitative index may be useful to detect abnormal upper airway collapsibility in awake subjects with SDB. However, some limits of this study are obvious such as the lack of subjects with mild OSAH (AHI $<15$ and $>5$ ) and the age of the controls who were much younger $(34 \pm$ 12 yrs) than the patients with OSAH. Furthermore, the application of NEP near end expiratory lung volume tends to elicit reflex activation of genioglossus [22]. This can unpredictably influence the area under the final part of the expiratory flow/volume curve during NEP both in controls and SDB subjects, affecting the quantitative index used to assess the upper airway collapsibility.

In a very recent paper Insalaco and coworkers used the drop of expiratory flow under NEP ( $\triangle \mathrm{V}$-NEP), expressed as percentage change of peak expiratory flow under NEP, as index of upper airway collapsibility to detect OSAH in patients with sleep disordered breathing. Although this index was a better indicator of OSAH severity when compared to the previous ones, they reported, at best, a determination coefficient equal to 0.32 between the $\mathrm{AHI}$ and $\triangle \mathrm{V}$-NEP [31], using NEP of $-10 \mathrm{cmH}_{2} \mathrm{O}$ in the supine position. An inherent problem with this approach is that $\Delta \mathrm{V}$ NEP does not take into account the duration of the expiratory flow drop under the NEP application, while it is very clear from the flow-time tracings given by the same Authors that this transient may last very differently with the same percentage value of reduction.

By time-integration of the expiratory flow in the first 0.5 and $1 \mathrm{sec}$ after the application of a given level of NEP one can easily calculate the expiratory volume exhaled in a preset time in a given body position during wakefulness and use this parameter as an index of the mechanical properties of the upper airways at the onset of expiration when the genioglossus does not appear reflexively activated [22]. Therefore, the novelty of this study is the utilization of a method which, still adopting the NEP technique, is more reliable to assess and measure the upper airway collapsibility because it is quantitative, and it is not influenced by the flow of the preceding tidal expiration and by the effect of neuromuscular factors.

$\mathrm{V}, \mathrm{NEP}_{0.5}$ and $\mathrm{V}, \mathrm{NEP}_{1}$ values were reduced in the supine position at each level of applied NEP in all groups, likely to reflect a posture-related increase in the upper airway resistance $[18,23,32,33]$. Therefore, $\mathrm{V}, \mathrm{NEP}_{0.5}$ and $\mathrm{V}, \mathrm{NEP}_{1}$ measurements appear to be influenced by the baseline expiratory upper airway resistance which has been shown to be higher in OSAH patients, probably because of minimal structural abnormalities (abnormal hyoid bone position and increase in soft pharyngeal tissues) [20] and related shape changes. It is conceivable that lower $\mathrm{V}, \mathrm{NEP}_{0.5}$ and $\mathrm{V}, \mathrm{NEP}_{1}$ found in our OSAH patients may be partly due to reduced baseline upper airway caliber which, on the other hand, is expected to increase the pharyngeal compliance and finally the upper airway collapsibility in these subjects [21]. However, the expired volume in the first 0.5 or $1 \mathrm{sec}$ was lower during NEP than during the previous control expiration in either position in about $15-18 \%$ of our apneic snorers. This never occurred in snorers and controls. This fact strongly suggests that in OSAH patients a brisk narrowing of upper airways is elicited by the sudden NEP application, the magnitude of which is largely depending on the pharyngeal collapsibility under the prevailing circumstances and substantially reflected by the $\mathrm{V}, \mathrm{NEP}_{0.5}$ or $\mathrm{V}, \mathrm{NEP}_{1}$ values. In line with this reasoning, the early expiratory flow during NEP was often below the isovolume spontaneous expiratory flow, particularly in OSAH patients (see Fig. 1), as also shown in previous studies $[22,27,28]$. 


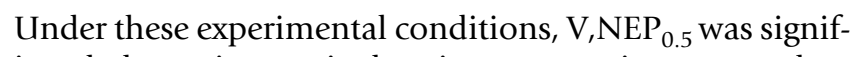
icantly lower in apneic than in non-apneic snorers when measured in the supine position utilizing the smallest level of NEP (i.e.: $-5 \mathrm{cmH}_{2} \mathrm{O}$ in our study). Thus, the lower the value of $\mathrm{V}, \mathrm{NEP}_{0.5}$ (or $\mathrm{V}, \mathrm{NEP}_{1}$ ), the higher the possibility for snoring people to have OSAH. Indeed, according to this method an increased pharyngeal collapsibility even during wakefulness affects the vast majority of snorers who have OSAH. This information is obtained in a rapid, simple and non-invasive way without cooperation of the subjects who can be studied when awake, repeatedly and in different body position. In this respect it has to be stressed that it is not necessary to control with regards to baseline spontaneous tidal volumes and flows. Indeed, $\Delta \mathrm{V}, \mathrm{NEP}_{0.5}$ and $\Delta \mathrm{V}, \mathrm{NEP}_{1}$ did not perform differently or better to distinguish between snorers and OSAH patients than $\mathrm{V}, \mathrm{NEP}_{0.5}$ and $\mathrm{V}, \mathrm{NEP}_{1}$.

Unfortunately, the ability to differentiate snorers with or without OSAH was not sufficient, at least within our capabilities, to recommend this technique and related parameters as a reliable diagnostic tool to obviate sleep studies or even to select subjects for polysomnographic evaluation. Lower levels of NEP (i.e.: -2 or $-3 \mathrm{cmH}_{2} \mathrm{O}$ ), however, might be more useful for this purpose and deserve to be tested in the future.

Three further comments need to be made. Firstly, generally a high collapsibility of the upper airways does not seem sufficient to cause OSAH since several snorers without OSAH exhibited similarly reduced values of $\mathrm{V}, \mathrm{NEP}_{0.5}$ or $\mathrm{V}, \mathrm{NEP}_{1}$. Secondly, other factors must influence the severity of OSAH, as assessed by ODI and AHI, because no different values of $\mathrm{V}, \mathrm{NEP}_{0.5}$ (or $\mathrm{V}, \mathrm{NEP}_{1}$ ) were found in any position or with different levels of NEP between mild-tomoderate and severe OSAH patients. Thirdly, some OSAH

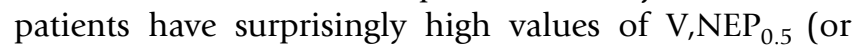
$\mathrm{V}, \mathrm{NEP}_{1}$ ) comparable to those of the controls, showing a normal upper airway collapsibility during wakefulness, and thus suggesting different state-related factors leading to OSAH or a site of upper airway obstruction during sleep only at naso-pharyngeal level which cannot be directly assessed with this technique.

Finally, contrary to the opinion of the other Authors who used the NEP technique to detect OSAH patients during wakefulness [27-30], we have to stress that, although the results obtained with $\mathrm{V}, \mathrm{NEP}_{0.5}$ were similar or even better than the previous ones [27-30], whatever NEP-related parameter is adopted, presently this tool is not sufficiently capable of revealing OSAH on an individual basis for clinical purpose.

In conclusion, the NEP technique when properly used is potentially useful to study upper airway collapsibility in patients with OSAH during wakefulness in order to better understand its main mechanisms, to assess in the long term the effects of various interventions, and possibly for selecting non-apneic snorers to follow up. On the other hand, it cannot be recommended for routine OSAH screening in awake snorers who should subsequently be subjected to sleep studies.

\section{Abbreviations}

OSAH = obstructive sleep apnea-hypopnea; AHI = apneahypopnea index; $\mathrm{NEP}=$ negative expiratory pressure; $\mathrm{SDB}$ = sleep disordered breathing; $\mathrm{BMI}=$ body mass index; $\mathrm{V}, \mathrm{NEP}_{0.5}$ and $\mathrm{V}, \mathrm{NEP}_{1}=$ exhaled volume in the first 0.5 and $1 \mathrm{sec}$. after application of NEP; ROC = receiver operating characteristic (curve)

\section{References}

I. Isono S, Saeki N, Tanaka A, Nishino T: Collapsibility of passive pharynx in patients with acromegaly. Am J Respir Crit Care Med 1999, 1 60:64-68.

2. Isono S, Tanaka A, Sho Y, Konno A, Nishino T: Advancement of the mandible improves velopharyngeal airway patency. J Appl Physiol 1995, 79:2132-2138.

3. Isono S, Remmers JE, Tanaka A, Sho Y, Sato J, Nishino T: Anatomy of pharynx in patients with obstructive sleep apnea and in normal subjects. J Appl Physiol 1997, 82:1319-1326.

4. Isono S, Shimada A, Utsugi M, Konno A, Nishino T: Comparison of static mechanical properties of the passive pharynx between normal children and children with sleep-disordered breathing. Am J Respir Crit Care Med 1998, I 57:1204-1212.

5. Liistro G, Stanescu D, Dooms G, Veriter C, Aubert-Tulkens G, Rodenstein D: Hypopharyngeal and neck cross-sectional changes monitored by inductive plethysmography. J Appl Physiol 1990, 68:2649-2655.

6. Brown IG, Bradley TD, Phillipson EA, Zamel N, Hoffstein V: Pharyngeal compliance in snoring subjects with and without obstructive sleep apnea. Am Rev Respir Dis 1985, I32:2 I I-2 I5.

7. Schwab RJ, Gefter WB, Hoffman EA, Gupta KB, Pack Al: Dynamic upper airway imaging during awake respiration in normal subjects and patients with sleep disordered breathing. Am Rev Respir Dis 1993, 74:1385-1400.

8. Schwab RJ, Gefter WB, Pack Al, Hoffman EA: Dynamic imaging of the upper airway during respiration in normal subjects. J Appl Physiol 1993, 74: I504-I5I4.

9. Gleadhill IC, Schwartz AR, Schubert N, Wise RA, Permutt S, Smith PL: Upper airway collapsibility in snorers and in patients with obstructive hyperpnea and apnea. Am Rev Respir Dis 1992, |43:1300-1303.

10. Smith PL, Wise RA, Gold AR, Schwartz AR, Permutt S: Upper airway pressure-flow relationships in obstructive sleep apnea. J Appl Physiol 1988, 64:789-795.

II. Schwartz AR, Smith PL, Wise RA, Gold AR, Permutt S: Induction of upper airway occlusion in sleeping individuals with subatmospheric nasal pressure. J Appl Physiol 1988, 64:535-542.

12. Schwab RJ, Gupta KB, Gefter WB, Metzeger LJ, Hoffman EA, Pack AI: Upper airway and soft tissue anatomy in normal subjects and patients with sleep disordered breathing. Significance of lateral pharyngeal walls. Am J Respir Crit Care Med 1995, I52:1673-1689.

13. Watanabe T, Isono S, Tanaka A, Tanzawa H, Nishino T: Contribution of body habitus and craniofacial characteristics to segmental closing pressures of the passive pharynx in patients with sleep-disordered breathing. Am J Respir Crit Care Med 2002, 1 65:260-265.

14. Haponik EF, Smith PL, Bohlman ME, Allen RP, Goldman SM, Bleecker ER: Computerized tomography in obstructive sleep apnea. Correlation of airway size with physiology during sleep and wakefulness. Am Rev Respir Dis 1983, I 27:221-226. 
I5. Rivlin J, Hoffstein V, Kalbfleisch J, McNicholas W, Zamel N, Bryan AC: Upper airway morphology in patients with idiopathic obstructive sleep apnea. Am Rev Respir Dis 1984, I 29:355-360.

16. Anch AM, Remmers JE, Bunce H 3rd: Supraglottic airway resistance in normal subjects and patients with occlusive sleep apnea. J Appl Physiol 1982, 53: I I58-I I63.

17. Stauffer JL, Zwillich CW, Cadieux RJ, Bixler EO, Kales A, Varano LA, White DP: Pharyngeal size and resistance in obstructive sleep apnea. Am Rev Respir Dis 1987, I 36:623-627.

18. Martin SE, Marshall I, Douglas NJ: The effect of posture on airway caliber with the sleep-apnea/hypopnea syndrome. Am J Respir Crit Care Med 1995, 152:721-724.

19. Rodenstein DO, Doom G, Thomas Y, Liistro G, Stanescu DC, Culee $C$, Aubert-Tulkens G: Pharyngeal shape and dimension in healthy subjects, snorers, and patients with obstructive sleep apnea. Thorax 1990, 45:722-727.

20. Verin E, Tardif C, Buffet X, Marie JP, Lacoume Y, Andrieu-Guitrancourt J, Pasquis $P$ : Comparison between anatomy and resistance of upper airway in normal subjects, snorers and OSAS patients. Respir Physiol 2002, I 29:335-343.

21. Sforza E, Bacon W, Weiss T, Thibault A, Petiau C, Krieger J: Upper airway collapsibility and cephalometric variables in patients with obstructive sleep apnea. Am J Respir Crit Care Med 2000, I 6 |:347-352.

22. Tantucci C, Mehiri S, Duguet A, Similowski T, Arnulf I, Zelter M, Derenne JP, Milic-Emili J: Application of negative expiratory pressure during expiration and activity of genioglossus in humans. J Appl Physiol 1998, 84:1076-1082.

23. Tantucci C, Duguet A, Ferretti A, Mehiri S, Arnulf I, Zelter M, Similowski T, Derenne JP, Milic-Emili J: Effect of negative expiratory pressure on respiratory system flow resistance in awake snorers and nonsnorers. J Appl Physiol 1999, 87:969-976.

24. American Academy of Sleep Medicine Task Force: Sleep-related breathing disorders in adults: recommendation for syndrome definition and measurement techniques in clinical research. Sleep 1999, 22:667-689.

25. Quanjer PT, Tammeling GJ, Cotes JE, Fabbri LM, Matthys H, Pederson OF, Peslin R, Roca J, Sterk PG, Ulmer WT: Lung volume and forced ventilatory flows. Report Working Party Standardisation of Lung Function Tests, European Community for Steel and Coal. Official Statement of the European Respiratory Society. Eur Resp J Suppl 1993, 16:5-40.

26. Koulouris NG, Valta P, Lavoie A, Corbeil C, Chasse M, Braidy J, MilicEmili J: A simple method to detect expiratory flow limitation during spontaneous breathing. Eur Respir J 1995, 8:306-3।3.

27. Liistro G, Veriter C, Dury M, Aubert G, Stanescu D: Expiratory flow limitation in awake sleep-disordered breathing subjects. Eur Respir J 1999, 14:185-190.

28. Verin E, Tardif C, Portier F, Similowski T, Pasquis P, Muir JF: Evidence for expiratory flow limitation of extrathoracic origin in patients with obstructive sleep apnea. Thorax 2002, 57:423-428.

29. Van Meerhaeghe A, Delpire P, Stenuit P, Kerkhofs M: Operating characteristic of the negative expiratory pressure technique in predicting obstructive sleep apnea syndrome in snoring patients. Thorax 2004, 59:883-888.

30. Tamisier R, Wuyam B, Nicolle I, Pepin JL, Orliaguet O, Perrin CP, Levy P: Awake flow limitation with negative expiratory pressure in sleep disordered breathing. Sleep Medicine 2005, 6:205-213

31. Insalaco G, Romano S, Marrone O, Salvaggio A, Bonsignore G: A new method of negative expiratory pressure test analysis detecting upper airway flow limitation to reveal obstructive sleep apnea. Chest 2005, I 28:2159-2165.

32. Jan MA, Marshall I, Douglas NJ: Effect of posture on upper airway dimensions in normal human. Am J Respir Crit Care Med 1994, | 49: | 45 - | 48.

33. Yildirim N, Fitzpatrick MF, Whyte KF, Jalleh R, Wightman AJ, Douglas $\mathrm{NJ}$ : The effect of posture on upper airway dimensions in normal subjects and in patients with the sleeapnea/hyperpnea syndrome. Am Rev Respir Dis 1991, I44:845-847.
Publish with Biomed Central and every scientist can read your work free of charge

"BioMed Central will be the most significant development for disseminating the results of biomedical research in our lifetime. "

Sir Paul Nurse, Cancer Research UK

Your research papers will be:

- available free of charge to the entire biomedical community

- peer reviewed and published immediately upon acceptance

- cited in PubMed and archived on PubMed Central

- yours - you keep the copyright

Submit your manuscript here:

http://www.biomedcentral.com/info/publishing_adv.asp
BiolMedcentral 